\title{
Physiotherapy for human T-lymphotropic virus I-associated myelopathy: review of the literature and future perspectives
}

This article was published in the following Dove Press journal:

Journal of Multidisciplinary Healthcare

23 February 2015

Number of times this article has been viewed

\author{
Katia N Sá \\ Maíra C Macêdo' \\ Rosana P Andrade ${ }^{2}$ \\ Selena D Mendes' \\ José $V$ Martins ${ }^{3}$ \\ Abrahão F Baptista ${ }^{1,4}$ \\ 'Neuromusculoskeletal Research \\ Group, Bahian School of Medicine \\ and Human Health, Salvador, \\ Brazil; ${ }^{2}$ Edgard Santos University \\ Hospital, Federal University of Bahia, \\ Salvador, ${ }^{3}$ Deolindo Couto Institute \\ of Neurology, Federal University \\ of Rio de Janeiro, Rio de Janeiro, \\ ${ }^{4}$ Biomorphology Department, Health \\ Sciences Institute, Federal University \\ of Bahia, Salvador, Brazil
}

Correspondence: Abrahão F Baptista Universidade Federal da Bahia, Rua Dr Antônio Monteiro, 228/602, Itaigara, Salvador Bahia, Brazil, CEP 41815130 Email afbaptista@ufba.br

\begin{abstract}
Human T-lymphotropic virus 1 (HTLV-1) infection may be associated with damage to the spinal cord - HTLV-associated myelopathy/tropical spastic paraparesis - and other neurological symptoms that compromise everyday life activities. There is no cure for this disease, but recent evidence suggests that physiotherapy may help individuals with the infection, although, as far as we are aware, no systematic review has approached this topic. Therefore, the objective of this review is to address the core problems associated with HTLV-1 infection that can be detected and treated by physiotherapy, present the results of clinical trials, and discuss perspectives on the development of knowledge in this area. Major problems for individuals with HTLV-1 are pain, sensory-motor dysfunction, and urinary symptoms. All of these have high impact on quality of life, and recent clinical trials involving exercises, electrotherapeutic modalities, and massage have shown promising effects. Although not influencing the basic pathologic disturbances, a physiotherapeutic approach seems to be useful to detect specific problems related to body structures, activity, and participation related to movement in HTLV-1 infection, as well as to treat these conditions.
\end{abstract}

Keywords: HTLV-1, HAM/TSP, physical therapy modalities, quality of life, pain, sensorymotor dysfunction, urinary symptoms

\section{Introduction}

Human T-lymphotropic virus 1 (HTLV-1) is a retrovirus of the Retroviridae family that affects T-lymphocytes from human blood and can cause neurological disorders. ${ }^{1,2}$ The distribution of this retrovirus in the world has an irregular shape. Although prevalence in Africa and India is not yet fully known, it is believed that there are now 5 to 10 million people infected worldwide, with the main endemic areas being southwest Japan, sub-Saharan Africa, South America, Caribbean, and places in the Middle East, Australia, and Melanesia. , $^{3,4}$

In Brazil, the geographical distribution of the infection is quite heterogeneous, and the country can be seen as one of the most endemic areas, ${ }^{3}$ with an assumed 2.5 million people living with HTLV. ${ }^{5}$ The highest number of cases are in the northeast, southeast, and north regions, and Salvador city has the highest prevalence (1.7\%). Women are primarily infected, especially those of low educational and socioeconomic levels. 5,6

Of individuals infected by HTLV-1, only 4\% to 5\% develop HTLV-associated myelopathy/tropical spastic paraparesis (HAM/TSP) in the fourth or fifth decade of life, which in Brazil is the principal progressive myelopathy due to non-tumoral causes. ${ }^{6}$ Although the pathogenesis of HAM/TSP remains uncertain, the disease process is understood as demyelization and axonal degeneration that result from an 
inflammatory reaction in the region infiltrated by mononuclear cells, with destruction of the white and gray matter of the spinal cord, leading to reduced sensory and motor capacities associated with functional consequences. ${ }^{7,8}$ All these results lead to impairments in body structures, activity, and social participation.

HAM/TSP is characterized by the classic symptoms of progressive weakness and chronic pain in the lower back and lower limbs, urinary urgency, spasticity, hyperreflexia (which may be present in all four limbs), the Babinski sign, and abnormalities of superficial and deep sensibility of the lower limbs. ${ }^{7}$ Other symptoms may also be associated, like erectile dysfunction, decreased libido, urinary incontinence, and constipation. ${ }^{9,10}$

Many patients need adaptations for daily activities of living, such as crutches, walkers, braces, and wheelchairs, which are associated with increased physical handicap, risk of falls, and reduced quality of life and work capacity. ${ }^{7}$ Living with this disease may generate social isolation and depression. ${ }^{11}$ All these features correlate with those of patients with similar neuro-functional conditions in who good results are obtained through physiotherapy. ${ }^{12}$

Although physiotherapy cannot directly affect the pathological aspects of the infection, it can make a significant contribution to the care of these patients, as the desired clinical outcomes of chronic diseases are improvement in functional status, symptom reduction, and a positive impact on quality of life. However, there is little evidence regarding specific physiotherapy programs for individuals with this disease. Therefore, the aim of this narrative review is to present the principal problems associated with HTLV-1 that can be treated with physiotherapy and the results of clinical trials, indicating perspectives for the development of knowledge in this area.

\section{Physiotherapeutic assessment of individuals with HTLV-I}

Although physiotherapy is a relatively new profession, having emerged after World War II, it is distinguished from other health professions because of its specific study of human movement and function, as well as its use of physical resources to provide modifications to the body's structures, activity, and social participation. ${ }^{13}$ Through a functional kinetic diagnosis and therapeutic modalities, including manual therapy, therapeutic exercise, electrotherapy, thermotherapy, phototherapy, hydrotherapy, and other physical resources, physiotherapy is a profession that has a significant role in the multidisciplinary health team, and meets specific is particularly suited to the needs of the individual with HTLV-1. The exclusive use of drug or surgical interventions cannot address the biopsychosocial model of health care proposed by the World Health Organization. ${ }^{14}$

Each health professional evaluates individuals from a particular point of view, and therefore develops a broad range of methods for the diagnosis and monitoring of therapeutic interventions. Some instruments have been developed to assess general conditions, being useful for all professionals and applicable to individuals with different clinical conditions. ${ }^{15,16}$ Others are specific, and skilled professionals from certain areas are more likely to use them with greater precision. ${ }^{17,18}$ As they are specific, only a few individuals with certain diseases or dysfunctions may benefit from their use. Due to the imprecision of assessment tools, the biological variability of affected individuals, and the intrinsic subjectivity of the human being, ${ }^{19,20}$ it is important to know the best resources to assess and treat each condition.

\section{Assessment of sociodemographic characteristics}

The sociodemographic assessment of patients infected by HTLV-1 may involve consideration of characteristics such as age and sex, since the prevalence tends to increase over the years of life and women are the most affected. ${ }^{3}$ Aspects such as socioeconomic and educational levels should be taken into consideration in the evaluation due to the epidemiological profile that has been reported. ${ }^{21,22}$ Additional factors such as smoking, alcohol consumption, diet, job satisfaction, and physical activity were not clearly associated with HTLV-1, but may be associated with secondary findings or progression of symptoms and motor performance.

\section{Assessment of pain and sensory abnormalities}

Pain is one of the principal complaints of patients with HTLV- $1^{2,7}$ and is in general a chronic condition, with a high impact on the patients' quality of life..$^{21,22}$ Importantly, individuals infected with HTLV-1, even when still asymptomatic for neurological symptoms (neurogenic bladder or HAM/ TSP), have twice the prevalence of chronic pain in relation to a noninfected population..$^{22}$ Therefore, this symptom should be evaluated in detail and monitored at all stages of the disease (Figure 1), and may be due to neuropathic and nociceptive sources, as well. ${ }^{2,21,22}$

People with chronic pain should be evaluated in terms of: its location (using a body map, featuring all presenting pain); its type-if neuropathic, nociceptive, mixed, or with characteristics 


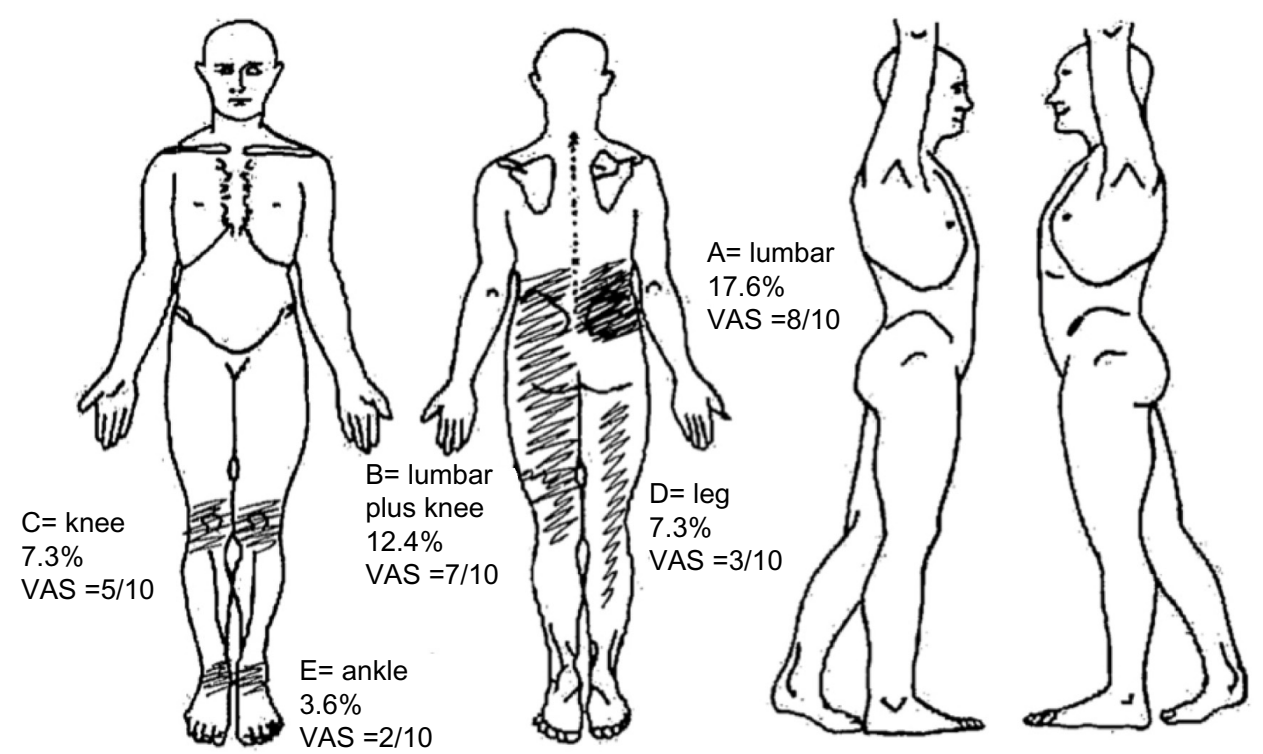

Figure I This figure presents a typical body map, with the location of pain sites ordered by importance (not always pain severity) according to the patients, from A to E, pain frequency and intensity in the visual analog scale (VAS).

Notes: Patients with human T-lymphotropic virus I often present with pain complaints in the lower back and lower limbs. The figure shows also the frequency of its distribution and the average reported intensity described using a VAS, where 0 indicates no pain and 10 the most intense pain (Mendes et al ${ }^{22}$ ). Note that the pain tends to be more severe and frequent in the lower back. In the lower limbs it follows many distinct patterns, including a longitudinal distribution, which may be related to neuropathic or musculoskeletal pain, as well as joint pain.

of centralization; its intensity (visual analog scale is the most common method of assessing this); attenuating/provoking factors (description, triggering and mitigating factors); its duration in months or years; the drugs that are or were used to control it; the impact on the patient's quality of life (qualitative and/or quantitative assessment); and some cognitive-behavioral aspects that may interfere, such as the level of catastrophizing thoughts, quality of sleep, beliefs about pain, anxiety and depression, among others. Due to the multidimensionality of pain, at least three valid instruments should be applied to its assessment before and after the interventions, even in research. ${ }^{20}$

The physiotherapist will be better able to assess the behavior of symptoms regarding all aspects of movement, with the focus on identifying dysfunction, as well as musculoskeletal or neurophysiological abnormalities that may be causing the symptoms. ${ }^{20}$ Among the questionnaires available, use of at least the Brief Pain Inventory is recommended. ${ }^{23}$ This questionnaire combines the use of a visual scale with a body map and considers the duration of symptoms, including those that are sensory and cognitive, and the impact of pain on personal life. The instrument has the capability to evaluate the structural levels of, and also activity and participation related to, pain - a key factor, as in chronic pain conditions there is often a disproportion between symptom intensity and functionality. ${ }^{24}$

To distinguish the type of pain, whether nociceptive or neuropathic, the Douleur Neuropathique 4 (DN4) questionnaire $^{25}$ is a simple and quick tool. It is important to consider that pain in these patients is not exclusively neuropathic, since in a study, $52.6 \%$ of study participants had six or more sites of pain in the body, and in many of them, the characteristic was predominantly nociceptive, with no association between location and type of pain. ${ }^{21,22}$ After filling in the body map, identifying the type of pain in each of the affected sites can help the therapist to seek distinct sources of the symptom. Nociceptive pain is usually referred at secondary areas, whereas neuropathic pain symptoms are more frequently located at the site of lesion. These differences are consequent to distinct patterns of descending inhibition and facilitation from brain stem. ${ }^{26}$ This phenomenon will lead to a trend of complaints about regions that are distant from the source of the symptoms, and not those where the lesion is localized. Interestingly, for neuropathic pain, it is the opposite, with pain being indicated as being at the same location as the lesion. Therefore, identification of the type of pain will help the clinician to look at the actual source of symptoms.

To assess the impact on quality of life, despite the fact that the Short-Form 36 Quality of Life Questionnaire (SF-36) $)^{21,22,24}$ is the most applied instrument, the short version of the World Health Organization of Quality of Life (WHOQOL $)^{27}$ questionnaire can be used in less time and is more easily understood by individuals with different educational levels, including those of low socioeconomic status. ${ }^{5,6}$ The 
factors that most impact the quality of life of these patients are pain and functional independence, ${ }^{24}$ which should be evaluated in more detail.

Quantitative sensory testing can complement some subjective findings regarding pain or even other sensory changes in patients with HTLV-1, which include changes in tactile, mechanical, and thermal thresholds, and reduction in vibration and proprioceptive sensibility. For simple quantitative sensory evaluation, instruments such as a pressure gauge (algometer), Von Frey filaments (five to 20 graduated nylon filaments), and a calibrated brush can be used..$^{28,29}$ The places most affected by pain and sensory changes are the lower back and lower limbs, due to spinal-cord lesions. ${ }^{17}$ Therefore the assessment should follow the key points recommended in the American Spinal Injury Association Impairment Scale for tactile (including protopathic and epicritic touch), thermal, and pain sensibilities. ${ }^{30}$ Changes in superficial sensibility in patients with HTLV-1 include hypo (hypoesthesia) or hyper phenomena (hyperalgesia, allodynia, and hyperpathia). Pressure pain threshold can also be assessed in the spinous processes of the lumbar spine, seeking to verify if there is hyperalgesia due to local or regional inflammatory processes. $^{28}$

Deep sensibility abnormalities include a decrease in proprioception and vibratory sensibility, both present in patients with HAM/TSP. ${ }^{7,8}$ To assess vibratory sensibility, a 64/128 Hz tuning fork should be used, and the tests should be made on the bony protuberances of the lower limbs, including the anterior superior iliac spine, greater trochanter of the femur, patella, medial and lateral malleolus, and heads of the first and fifth metatarsals. ${ }^{29}$ The physiotherapist must include in the proprioceptive evaluation the impact of the changes in motor function, especially balance, gait, and transfers. ${ }^{17}$

HTLV-1 may be associated with peripheral nerve inju$\operatorname{ries}^{2,8}$ and so the therapist should consider that the pattern of sensory and motor impairments may be due to this type of injury, and not only from the spinal-cord injury. Besides the distribution of the symptoms being longitudinal to the limbs, and non-transverse, this type of injury often exhibits a typical mechanical behavior - neurodynamics, which can be detected by maneuvers that put pressure or tension on the peripheral nerves. ${ }^{31}$ Although this has not yet been determined in individuals infected with HTLV-1, the maneuvers that put tension on the spinal cord and in the peripheral nerves, like the sciatic, fibular, sural, and femoral nerves, must be considered in the evaluation. ${ }^{32}$ If symptoms are reproduced with these maneuvers, the patient is likely to benefit from neural mobilization.

\section{Evaluation of motor function}

To evaluate the static and dynamic motor function it is important to use tools for kinematic and kinetic evaluation, specific functional tests, and validated and reliable questionnaires. Postural changes are frequent in these patients and a simple way to evaluate them has been described previously. ${ }^{33}$ This method uses a simple camera and free two-dimensional motion analysis software - SAPO (Sistema de Avaliação Postural). ${ }^{34}$ The typical posture of the patient with HAM/TSP is characterized by a tendency to flexion in the knees and ankles, associated with an anterior or posterior trunk tilt. These postural deviations may be due to shortening and stiffness of muscle groups formed by the flexors and hip adductors, knee flexors, and extensors of the ankle; weakness of flexors, extensors, abductors, and external rotators of the hip and knee extensors; ${ }^{33}$ and weakness of gluteal and abdominal muscles, generating hip flexion, pelvic instability, and misalignment of the lower limbs. ${ }^{35}$ All these disorders can cause joint deformities that impact significantly on the gait, ${ }^{7}$ balance, ${ }^{35}$ and posture. ${ }^{33}$ Noteworthy is the loss of postural control due to proprioceptive impairment in HAM/TSP, which prevents the continual adjustments within the base of support to maintain mobility and increases the risk of falls. ${ }^{12,36}$

Use of photography and the SAPO protocol also allows for evaluation of the range of active movement, which can be complementary to passive goniometric evaluation, when necessary. ${ }^{34}$ The range of motion assessments, including the final sensations of movement, will help the physiotherapist identify changes in muscle tonus and possible causes of limitations. Changes in tonus may be viscoelastic or neuromuscular. ${ }^{37}$ The former is related to limitations of soft tissues such as joint capsules, ligaments, fascia, and muscles, and can lead to significant repercussions in global function. Spasticity is the typical abnormality in the tonus of individuals with HAM/TSP, and the Modified Ashworth Scale is the most widely used for quantification. ${ }^{38}$

To assess the strength, specific and universal dynamometers are advantageous. ${ }^{17}$ Due to changes in the strength found in spastic muscles, ${ }^{2,35}$ and the typical posture and pain pattern in patients with HAM/TSP, ${ }^{33}$ it is recommended at least the strength assessment of the erector spinae muscles, knee extensors and flexors, and calf, as well as flexors, extensors, abductors, and external rotators of the hips be undertaken. A more complete assessment of the lower limbs may provide additional data that can help establish a more precise treatment program. When the initial evaluation does not result in an effective treatment, more advanced resources such as surface electromyography or musculoskeletal ultrasound 
can help determine altered patterns of muscle activation. ${ }^{17,39}$ These types of assessment may be especially beneficial in the control of lower back pain of nociceptive origin in these individuals.

To assess gait and balance, especially in individuals with neurological disorders, the most useful methods are the Timed Up and Go (TUG) ${ }^{40}$ test and the Berg Balance Scale. ${ }^{41}$ Despite the fact that the use of the Berg Scale is not reported in patients with HAM/TSP, a recent study demonstrated that at baseline they present much lower grades than those found in elderly patients with Parkinson's disease and stroke. ${ }^{42}$ The use of other scales has also been suggested, such as the adaptation of the scale used in paraplegia ${ }^{18}$ and the Functional Independence Measure (FIM), ${ }^{35}$ which can extend the functionality evaluation. The use of more precise measures such as a three-dimensional kinematic dispositive, isokinetic dynamometry, and stabilometry can improve the accuracy of kinetic functional diagnosis, ${ }^{17,39}$ but involve more extensive assessments and more expensive resources.

\section{Assessment of bowel and vesicourethral function}

The Osame Motor Disability Score (OMDS), regardless of it being a general tool, is also used to assess urinary function, grading levels of continence and incontinence, residual sensation, and voiding frequency. ${ }^{10}$ Quality of life related to urinary dysfunction may be also assessed through specific questionnaires on urinary symptoms, and perineal detailed physical evaluation favors the proper choice of individualized therapeutic resources. ${ }^{9}$

The thoracic and lumbosacral segments of the spinal cord are the principal sites of injury in patients with radiographic findings of spinal-cord atrophy ${ }^{43,44}$ The inflammatory process interrupts the connection of the sacral cord levels S2 to S4 and pudendal nerve to the sacral and pontine micturition center. ${ }^{9}$ The sacral centers start to behave in a reflexive way, with inadequate storage and bladder symptoms of urinary loss., ${ }^{9,4}$

In the course of the disease, detrusor-sphincter hyperreflexia and bladder sphincter dyssynergia prevail, which need to be confirmed by urodynamic study. It is common to find urgency, urge incontinence, nocturia, urinary frequency, and symptoms of hesitancy, weak or intermittent stream, sensation of incomplete emptying, stress voiding, and urinary retention. ${ }^{44}$ The presence of vesico-sphincter dyssynergia and areflexia can be found even in individuals with HTLV-1 but without $\mathrm{HAM} / \mathrm{TSP}^{7,10,43}$ As a consequence, lower urinary tract and intravesical hyperpressure arises, which in severe cases leads to impaired kidney function., ${ }^{2,9}$ These physiological changes in urination are one of the biggest factors of morbidity. ${ }^{10}$

Neurogenic bowel is also part of the picture presented by individuals infected with HTLV-1, and consists of the loss of sensation of the need for evacuation or the inability to distinguish between the presence of solid or liquid stool, and/or gas in the rectum. The intestinal dysfunctions may be associated with constipation and/or fecal incontinence. Though the former is the most often reported symptom, both bring a lot of discomfort and disorder that impact the quality of life for these individuals. ${ }^{44}$

\section{Evidence for physiotherapeutic treatment}

Having made an accurate diagnosis, the next step consists of prescribing a treatment. Applying interventions in these individuals without a more accurate physiotherapeutic diagnosis is often dangerous, because even with positive intention to treat, some features may be harmful, since the clinical picture is very complex. ${ }^{7}$ For this reason, physiotherapy should move toward evidence-based and patient-centered clinical practice (Table 1).

As far as we are aware, to date, few studies have considered the results of physiotherapy interventions in individuals infected with HTLV-1, and specifically with HAM/TSP. However, despite the fact that they are preliminary, the existent findings point to a positive path that can aid in the relief of symptoms and improvement of functional clinical signs in individuals affected by this disease.

\section{Exercise and manual therapy}

Physical exercises have the best results in the perception of the subjects treated, and in the evolution of the measured objective data. The use of a simple protocol of only six functional exercises (using stairs, standing on tiptoes, squatting, sitting, and standing) demonstrated a positive impact on functionality with reduced risk of falling rated by the FIM and TUG test. ${ }^{45}$ Positive response was also observed in all parameters of health-related quality of life, with decreased pain intensity, in patients who underwent a protocol using classic Pilates exercises performed on equipment with springs ${ }^{46}{ }^{4}$ In another study, patients who underwent exercise with the help of a Nintendo Wii showed improved balance and emotional aspects of quality of life. ${ }^{42}$

Perineal exercises can be used for overactive bladder, with the goal of reflex inhibition of the detrusor by voluntary contractions of the external urethral sphincter, facilitating voiding control. When indicated, increased pelvic muscle strength improves urethral closure pressure and stress, 


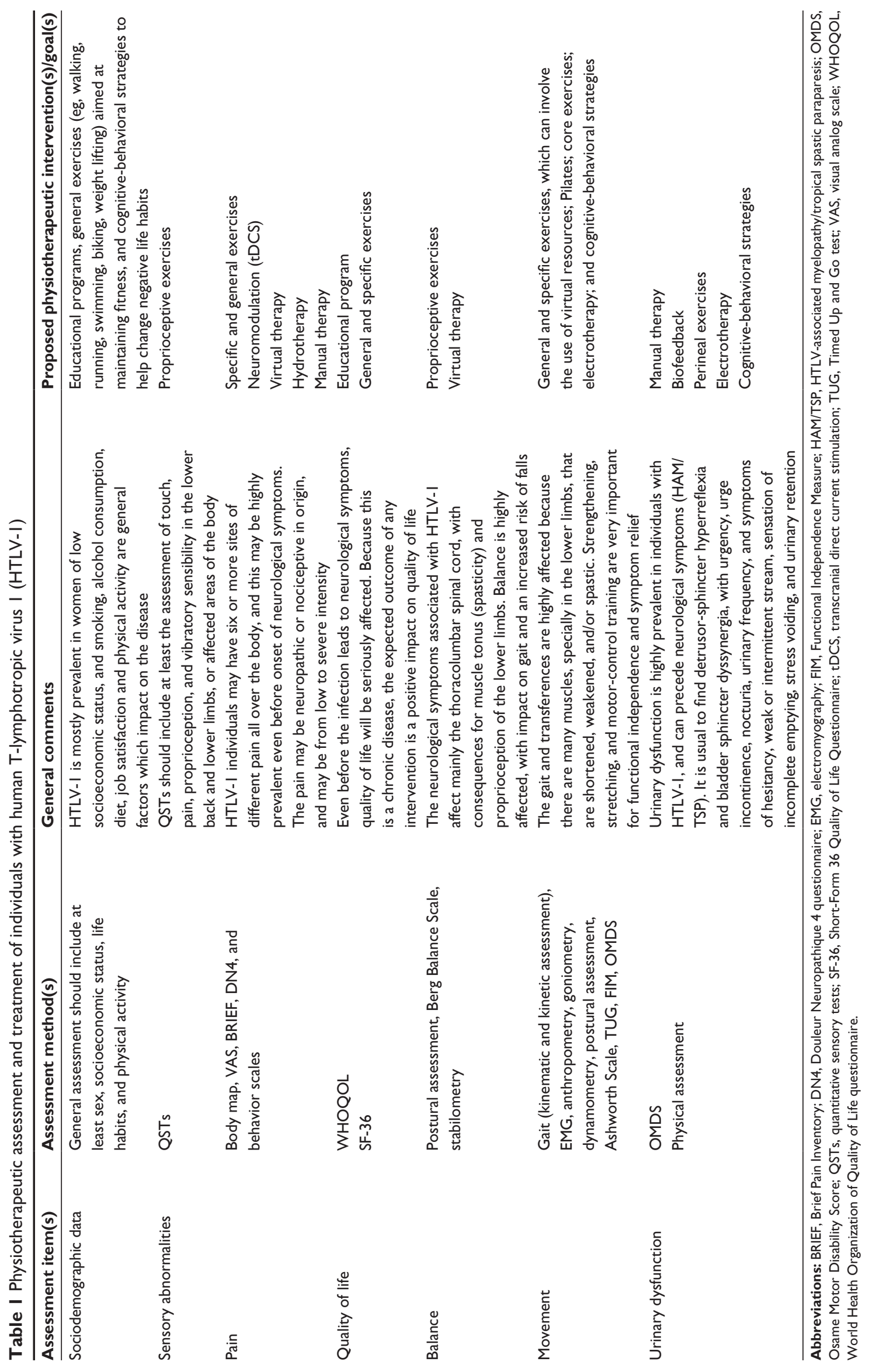


reducing losses. Stimuli such as the Credé and Valsalva maneuvers, and massage of the genitalia or inner thigh region are indicated when there are no signs of bladder sphincter dyssynergia, abnormal pressure, or abnormal emptying. ${ }^{47,48}$ All these methods are aimed at improving urinary storage at low pressures, and establishing continence to preserve kidney function and improve quality of life for patients. Perineal exercises, manual therapy techniques, anal relaxation, and abdominal massage to facilitate colonic transit may also help. ${ }^{49}$ Results seem to show positive effects of massage on bowel function in patients with HAM/TSP. ${ }^{50}$

\section{Electrotherapy}

Electrotherapy involves a number of features that can be useful in the treatment of individuals infected with HTLV-1 in many of its phases. As far as we are aware, only one study has been done to investigate the control of pain with transcranial direct current stimulation, and this showed a reduction in intensity of symptoms in just two sessions. ${ }^{51}$ However, after the third session the control group showed similar results to the group receiving active electrostimulation, raising doubts that the results were due to the electrotherapy - the improvement in both groups may indicate patients' positive expectancy with the application of electrotherapeutic resources, and therefore different models should be tested.

Other forms of electrotherapy involving muscle contraction to reduce spasticity and increase strength and motor control have shown promising results in a number of myelopathies, ${ }^{52}$ and should be considered in future studies of individuals with HTLV-1. Although it has not been tested in these patients, perineal electrostimulation at low frequencies generates suppression of efferent activity in the pelvis through central inhibition, physiologically activates the inhibitory reflex, decreases the number of delayed urinations, increases bladder capacity, and reduces the symptoms of urgency and urge incontinence. ${ }^{53}$ It may also be useful in restoring the sensation of bladder filling. ${ }^{54,55}$

\section{Cognitive-behavioral strategies}

Limited mobility and the sometimes low socioeconomic status of infected individuals have stimulated the search for protocols that can be performed autonomously in the patient's home. Our group developed a handbook of home exercises that is being tested in a randomized clinical trial. ${ }^{56}$ The proposal consists of a training intervention group opting for the model of health education. ${ }^{57}$ In this model, the individuals become active subjects in the learning process, being recognized as carriers of knowledge no less important than the technical-scientific knowledge of the investigator/health care professional. ${ }^{57}$ The interaction between individuals and staff begins via a focus group, which enables the strengthening of ties, and a survey on the participants' expectations regarding home exercise programs and perceptions on the benefits achieved by performing such exercises.

Behavioral therapy, in the form of a voiding diary - which aims to guide voiding control and changes in lifestyle, and balance water and food intake - may also be useful in the treatment of neuropathic bladder. ${ }^{48}$ Coloproctological physiotherapy can also make use of behavioral therapy, to advise individuals regarding a balanced diet and proper hydration to improve bowel function. ${ }^{49}$

\section{Final considerations}

HTLV-1 infection can lead to a diverse clinical picture and tends to be chronic. Actually there is no cure for this infection, and physiotherapy may have an important role in managing individuals with this infection, due to its neurological manifestations. The limited specific evidence in this area shows that there is the potential to use a physiotherapeutic approach in the care of individuals with HTLV-1, mainly to control pain, to improve movement, urinary symptoms, and quality of life. Future studies are needed both on the delineation of the functional consequences of HTLV-1 and its treatment by physiotherapy, which should be included in health care plans for individuals with this condition.

\section{Authors' contributions}

Katia N Sá idealized the project. All authors made substantial contributions to conception and design, acquisition of data, or analysis and interpretation of data; took part in either drafting the article or revising it critically for important intellectual content; and gave final approval of the version to be published.

\section{Disclosure}

The authors declare no conflicts of interest in this work.

\section{References}

1. Poiesz BJ, Ruscetti FW, Gazdar AF, Bunn PA, Minna JD, Gallo RC. Detection and isolation of type $\mathrm{C}$ retrovirus particles from fresh and cultured lymphocytes of a patient with cutaneous T-cell lymphoma. Proc Natl Acad Sci U SA. 1980;77(12):7415-7419.

2. Araujo AQ, Silva MT. The HTLV-1 neurological complex. Lancet Neurol. 2006;5(12):1068-1076.

3. Gessain A, Cassar O. Epidemiological aspects and world distribution of HTLV-1 infection. Front Microbiol. 2012;15(3):388.

4. Hlela C, Shepperd S, Khumalo NP, Taylor GP. The prevalence of human T-cell lymphotropic virus type 1 in the general population is unknown. AIDS Rev. 2009; 11(4):205-214. 
5. Carneiro-Proietti AB, Catalan-Soares BC, Castro-Costa CM, et al. HTLV in the Americas: challenges and perspectives. Rev Panam Salud Publica. 2006;19(1):44-53.

6. Moxoto I, Boa-Sorte N, Nunes C, et al. [Sociodemographic, epidemiological and behavioral profile of women infected with HTLV-1 in Salvador, Bahia, an endemic area for HTLV.] Rev Soc Bras Med Trop. 2007;40(1):37-41. Portuguese.

7. Reiss DB, Freitas GS, Bastos RH, et al. Neurological outcomes analysis of HTLV-1 seropositive patients of the Interdisciplinary Research HTLV Group (GIPH) cohort, Brazil. Retrovirology. 2014; 11(Suppl 1):P51.

8. Yamano Y, Sato T. Clinical pathophysiology of human T-lymphotropic virus-type 1-associated myelopathy/tropical spastic paraparesis. Front Microbiol. 2012;9(3):389.

9. Diniz MS, Feldner PC, Castro RA, Sartori MG, Girão MJ. Impact of HTLV-I in quality of life and urogynecologic parameters of women with urinary incontinence. Eur J Obst Gynecol Reprod Biol. 2009;147(2):230-233.

10. Andrade R, Tanajura D, Santana D, Santos Dd, Carvalho EM. Association between urinary symptoms and quality of life in HTLV-1 infected subjects without myelopathy. Int Braz J Urol. 2013;39(6):861-866.

11. Gascón MR, Capitão CG, Casseb J, Nogueira-Martins MC, Smid J, Oliveira AC. Prevalence of anxiety, depression and quality of life in HTLV-1 infected patients. Braz J Infect Dis. 2011;15(6):578-582.

12. Tyson SF, Connell LA. How to measure balance in clinical practice. A systematic review of the psychometrics and clinical utility of measures of balance activity for neurological conditions. Clin Rehabil. 2009;23(9):824-840.

13. Cavalcante CC, Rodrigues AR, Dadalto TV, da Silva EB. Evolução científica da fisioterapia em 40 anos de profissão [The scientific evolution of the Brazilian physical therapy in 40 years as a profession]. Fisioterapia em Movimento. 2011;24(3):513-522. Portuguese.

14. World Health Organization (WHO). The Ottawa Charter for Health Promotion. Ottawa: WHO; 1986. Available from: http://www.who.int/ healthpromotion/conferences/previous/ottawa/en/. Accessed November 4, 2014.

15. Berkman ND, Sheridan SL, Donahue KE, et al. Health literacy interventions and outcomes: an updated systematic review. Evid Rep Technol Assess (Full Rep). 2011;199:1-941.

16. McPheeters ML, Kripalani S, Peterson NB, et al. Closing the quality gap: revisiting the state of the science (vol 3: quality improvement interventions to address health disparities). Evid Rep Technol Assess (Full Rep). 2012;208(3):1-475.

17. Ricci NA, Aratani MC, Caovilla HH, Cohen HS, Ganança FF. Evaluation of properties of the Vestibular Disorders Activities of Daily Living Scale (Brazilian version) in an elderly population. Braz J Phys Ther. 2014;18(2):174-182.

18. Adry RA, Lins CC, Kruschewsky Rde A, Castro Filho BG. Comparison between the spastic paraplegia rating scale, Kurtzke scale, and Osame scale in the tropical spastic paraparesis/myelopathy associated with HTLV. Rev Soc Bras Med Trop. 2012;45(3):309-312.

19. de Paula JJ, Bertola L, de Ávila RT, et al. Development, validity, and reliability of the General Activities of Daily Living Scale: a multidimensional measure of activities of daily living for older people. Rev Bras Psiquiatr. 2014;36(2):143-152.

20. DeSantana JM, Sluka KA. Pain assessment. In: Sluka KA, editor. Mechanisms and Management of Pain for the Physical Therapist. Seattle, WA: IASP Press; 2009:95-131.

21. Neto EC, Brites C. Characteristics of Chronic Pain and its impact on quality of life of patients with HTLV-1-associated Myelopathy/Tropical Spastic Paraparesis (HAM/TSP). Clin J Pain. 2011;27(2): 131-135.

22. Mendes SM, Baptista AF, Sá KN, et al. Pain is highly prevalent in individuals with tropical spastic paraparesis. Health Care. 2013;1(3): $47-53$.

23. Memória CM, Yassuda MS, Nakano EY, Forlenza OV. Brief screening for mild cognitive impairment: validation of the Brazilian version of the Montreal cognitive assessment. Int J Geriatr Psychiatry. 2013;28(1): $34-40$.
24. Martins JV, Baptista AF, Araújo Ade Q. Quality of life in patients with HTLV-I associated myelopathy/tropical spastic paraparesis. Arq Neuropsiquiatr. 2012;70(4):257-261

25. Santos JG, Brito JO, de Andrade DC, et al. Translation to Portuguese and validation of the Douleur Neuropathique 4 questionnaire. $J$ Pain. 2010;11(5):484-490.

26. Vanegas H, Schaible HG. Descending control of persistent pain: inhibitory or facilitatory? Brain Res Brain Res Rev. 2004;46(3):295-309.

27. Zimpel RR, Fleck MP. Quality of life in HIV-positive Brazilians: application and validation of the WHOQOL-HIV, Brazilian version. AIDS Care. 2007;19(7):923-930.

28. Rolke R, Magerl W, Campbell KA, et al. Quantitative sensory testing: a comprehensive protocol for clinical trials. Eur J Pain. 2006;10(1): 77-88.

29. Shy ME, Frohman EM, So YT, et al; Therapeutics and Technology Assessment Subcommittee of the American Academy of Neurology. Quantitative sensory testing: report of the Therapeutics and Technology Assessment Subcommittee of the American Academy of Neurology. Neurology. 2003;60(6):898-904.

30. Kirshblum SC, Burns SP, Biering-Sorensen F, et al. International standards for neurological classification of spinal cord injury (revised 2011). J Spinal Cord Med. 2011;34(6):535-546.

31. Butler DS. Mobilisation of the Nervous System. London: Churchill Livingstone; 1991.

32. Ellis RF, Hing WA. Neural mobilization: a systematic review of randomized controlled trials with an analysis of therapeutic efficacy. J Man Manip Ther. 2008;16(1):8-22.

33. Macêdo MC, Baptista AF, Sá KN, et al. Postural Profile of Individuals with HAM/TSP. Braz J Med Human Health. 2013;2(1):99-110.

34. Ferreira EA, Duarte M, Maldonado EP, Burke TN, Marques AP. Postural assessment software (PAS/SAPO): Validation and reliabiliy. Clinics. 2010;65(7):675-681.

35. Franzoi AC, Arauújo AQ. Disability profile of patients with HTLV-Iassociated myelopathy/tropical spastic paraparesis using the Functional Independence Measure (FIM). Spinal Cord. 2005;43(4):236-240.

36. Facchinetti LD, Araújo AQ, Chequer GL, de Azevedo MF, de Oliveira RV, Lima MA. Falls in patients with HTLV-I-associated myelopathy/ tropical spastic paraparesis (HAM/TSP). Spinal Cord. 2013;51(3): 222-225.

37. Simons DG, Mense S. Understanding and measurement of muscle tone as related to clinical muscle pain. Pain. 1998;75(1):1-17.

38. Pisano F, Miscio G, Del Conte C, Pianca D, Candeloro E, Colombo R. Quantitative measures of spasticity in post-stroke patients. Clin Neurophysiol. 2000;111(6):1015-1022.

39. Hamano T, Fujiyama J, Kawamura Y, et al. Muscle MRI findings of HTLV-1-associated myelopathy. J Neurol Sci. 2002;199(1):45-48.

40. Metsavaht L, Leporace G, Riberto M, et al. Translation and cross-cultural adaptation of the lower extremity functional scale into a Brazilian Portuguese version and validation on patients with knee injuries. J Orthop Sports Phys Ther. 2012;42(11):932-939.

41. Pang MY, Eng JJ. Fall-related self-efficacy, not balance and mobility performance, is related to accidental falls in chronic stroke survivors with low bone mineral density. Osteoporos Int. 2008;19(7):919-927.

42. Arnault V, Sá KN. Uso do Nintendo Wii em pacientes com HAM/ TSP: Ensaio clinico randomizado [Use of Nintendo Wii in patients with HAM/TSP: randomized clinical trial] [Masters thesis]. Salvador: Bahian School of Medicine and Human Health; 2014.

43. Castro NM, Freitas DM, Rodrigues W Jr, Muniz A, Oliveira P, Carvalho EM. Urodynamic features of the voiding dysfunction in HTLV-1 infected individuals. Int Braz J Urol. 2007;33(2):238-245.

44. Rocha PN, Rehem AP, Santana JF, et al. The cause of urinary symptoms among Human T Lymphotropic Virus Type I (HLTV-I) infected patients: a cross sectional study. BMC Infect Dis. 2007;12(7):15.

45. Thomé BI, Borgui IS, Berardi J, Moser AD, Assis GM. Fisioterapia na reeducação do intestino neurogênico como resultado de uma lesão medular [Physiotherapy in the rehabilitation of neurogenic bowel as a result of a spinal cord injury]. Manual Therapy, Posturology and Rehabilitation Journal. 2012;10(47):19-27. Portuguese. 
46. Neto IF, Mendonça RP, Nascimento CA, Mendes SM, Sá KN Fortalecimento muscular em pacientes com HTLV-1 e sua influência no desempenho funcional: um estudo piloto [A pilot study: muscle strengthening in patients with HTLV-1 and its influence on functional performance]. Revista Pesquisa em Fisioterapia. 2012;2(2):143-155. Portuguese.

47. Borges J, Baptista AF, Santana N, et al. Pilates exercises improve low back pain and quality of life in patients with HTLV-1 virus: a randomized crossover clinical trial. J Bodyw Mov Ther. 2014;18(1):68-74.

48. Skaudickas D, Kèvelaitis E. [Modern approach to treatment of urinary incontinence.] Medicina (Kaunas). 2010;46(7):496-503. Lithuanian.

49. Mesquita LA, César PM, Monteiro MV, Silva Filho AL. Terapia comportamental na abordagem primária da hiperatividade do detrusor [Behavior therapy in primary approach of the detrusor's overactivity]. Femina. 2010;38(1):23-29. Portuguese.

50. Liu Z, Sakakibara R, Odaka T, et al. Mechanism of abdominal massage for difficult defecation in a patient with myelopathy (HAM/TSP). J Neurol. 2005;252(10):1280-1282.

51. Souto G, Borges IC, Goes BT, et al. Effects of tDCS-induced motor cortex modulation on pain in HTLV-1: a blind randomized clinical trial. Clin J Pain. 2014;30(9):809-815.

52. Morawietz C, Moffat F. Effects of locomotor training after incomplete spinal cord injury: a systematic review. Arch Phys Med Rehabil. 2013;94(11):2297-2308
53. Teri L, Gibbons LE, McCurry SM, et al. Exercise plus behavioral management in patients with Alzheimer disease: a randomized controlled trial. JAMA. 2003;290(15):2015-2022.

54. Amarenco G, Ismael SS, Even-Schneider A, et al. Urodynamic effect of acute transcutaneous posterior tibial nerve stimulation in overactive bladder. J Urol. 2003;169(6):2210-2215.

55. Primus G, Kramer G, Pummer K. Restoration of micturition in patients with acontractile and hypocontractile detrusor by transurethral electrical bladder stimulation. Neurourol Urodyn. 1996;15(5):489-497.

56. Borges AM, Salício VA, Gonçalves MA, Lovato M. A contribuição do fisioterapeuta para o programa de saúde da família - uma revisão da literature [The contribution of the physical therapist for the family health program - a literature review]. Uniciências. 2010;14(1):69-82. Portuguese.

57. Alves VS. Um modelo de educação em saúde para o Programa Saúde da Família: pela integralidade da atenção e reorientação do modelo assistencial [A health education model for the Family Health Program: towards comprehensive health care and model reorientation] Interface - Comunicação, Saúde e Educação. 2005;9(16):39-52. Portuguese.
Journal of Multidisciplinary Healthcare

\section{Publish your work in this journal}

The Journal of Multidisciplinary Healthcare is an international, peerreviewed open-access journal that aims to represent and publish research in healthcare areas delivered by practitioners of different disciplines. This includes studies and reviews conducted by multidisciplinary teams as well as research which evaluates the results or conduct of such teams or

\section{Dovepress}

healthcare processes in general. The journal covers a wide range of areas and welcomes submissions from practitioners at all levels, from all over the world. The manuscript management system is completely online and includes a very quick and fair peer-review system. Visit http://www.dovepress.com/testimonials.php to read real quotes from published authors. 